\title{
Corrigendum: The Influence of Chronic Pain and Cognitive Function on Spatial-Numerical Processing
}

\author{
Melanie Spindler ${ }^{1,2 * \dagger}$, Katharina Koch ${ }^{1 \dagger}$, Elena Borisov ${ }^{3}$, Jale Özyurt ${ }^{2}$, Peter Sörös ${ }^{4}$, \\ Christiane Thiel $^{2}$ and Carsten Bantel ${ }^{1}$ \\ ${ }^{1}$ Department of Anesthesiology, Critical Care, Emergency Medicine and Pain Management, Medicine and Health Sciences, \\ Carl von Ossietzky Universität Oldenburg, Oldenburg, Germany, ${ }^{2}$ Department of Psychology, Biological Psychology Lab, \\ School of Medicine and Health Sciences, University of Oldenburg, Oldenburg, Germany, ${ }^{3}$ Wrocław Medical University, \\ Wrocław, Poland, ${ }^{4}$ Department of Neurology, School of Medicine and Health Sciences, Carl von Ossietzky Universität \\ Oldenburg, Oldenburg, Germany
}

Keywords: chronic pain, number sense, pain rating scales, number line task, pain assessment

\section{A Corrigendum on}

The Influence of Chronic Pain and Cognitive Function on Spatial-Numerical Processing by Spindler, M., Koch, K., Borisov, E., Özyurt, J., Sörös, P., Thiel, C., et al. (2018). Front. Behav. Neurosci. 12:165. doi: 10.3389/fnbeh.2018.00165

\section{OPEN ACCESS}

Approved by:

Oliver T. Wolf,

Ruhr-Universität Bochum, Germany

*Correspondence:

Melanie Spindler melanie.spindler@uni-oldenburg.de

tThese authors have contributed equally to this work

Received: 28 January 2019 Accepted: 31 January 2019 Published: 19 February 2019

Citation:

Spindler M, Koch K, Borisov E,

Özyurt J, Sörös $P$, Thiel $C$ and Bantel C (2019) Corrigendum: The

Influence of Chronic Pain and

Cognitive Function on

Spatial-Numerical Processing.

Front. Behav. Neurosci. 13:29.

doi: 10.3389/fnbeh.2019.00029
In the original article, there was a mistake in Tables 1-4 as published. The tables show the data for $n=37$ chronic pain patients and $n=37$ matched healthy controls. However, the tables should have shown data for $n=42$ chronic pain patients and $n=42$ matched healthy controls. The corrected Tables 1-4 appears below.

Additionally, there was a mistake in the legend for Table $\mathbf{1}$ as published. The scaling of the variables "education" and "opioid medication" was incorrect. The correct legend appears below.

"SD: Standard deviation; ADS-K: General Depression Scale - Short form; *education refers to $0=$ no degree, $1=$ lower secondary education, $2=$ secondary school, $3=$ A-levels, $4=$ university degree; ${ }^{* *}$ on an 11-point Numerical Rating Scale $(0=$ no pain; $10=$ worst pain imaginable) on the day of testing.

${ }^{t}$ The total amount of participants reporting different pain syndromes. In brackets, only the corresponding main pain category of each participant is listed."

Lastly, in the original article, there was an error. The number sense performance of patients with vs. without opioid medication, was compared using the same incorrect sample size as mentioned above.

A correction has been made to the Results, Experimental Tests and Questionnaires, Clinical pain assessment, and number sense.

"Finally, the role of opioid medication on number sense performance was evaluated, suggesting that patients with opioid medication performed equally well on both number naming $[n=13$; $\left.M=4.7, S D=1.7, t_{(40)}=-0.542, p=0.591\right]$ and position marking $[n=13 ; M=4.8, S D=1.3$, $\left.t_{(39)}=0.818, p=0.419\right]$ compared to patients without opioid medication (number naming: $n=29$; $M=4.4, S D=1.3$; position marking: $n=28 ; M=5.3, S D=2.1)$." 
The authors apologize for these errors and state that they do not change the scientific conclusions of the article in any way. The original article has been updated.

Conflict of Interest Statement: The authors declare that the research was conducted in the absence of any commercial or financial relationships that could be construed as a potential conflict of interest.
Copyright (๑) 2019 Spindler, Koch, Borisov, Özyurt, Sörös, Thiel and Bantel. This is an open-access article distributed under the terms of the Creative Commons Attribution License (CC BY). The use, distribution or reproduction in other forums is permitted, provided the original author(s) and the copyright owner(s) are credited and that the original publication in this journal is cited, in accordance with accepted academic practice. No use, distribution or reproduction is permitted which does not comply with these terms.

TABLE 1 | Characteristics of participants.

\begin{tabular}{|c|c|c|}
\hline Characteristics & Controls & $\begin{array}{l}\text { Chronic pain } \\
\text { patients }\end{array}$ \\
\hline Sample size; $n$ & 42 & 42 \\
\hline Age [years]; mean (range) & $54.1(35-66)$ & $54.0(33-68)$ \\
\hline Mean education* (SD) & $2.71(1.0)$ & $2.05(1.1)$ \\
\hline Verbal IQ (SD) & $106.0(9.5)$ & $98.0(9.3)$ \\
\hline Pain intensity ${ }^{\star \star}(S D)$ & / & $5.9(1.6)$ \\
\hline Participants on opioid medication & I & 15 \\
\hline Participants with depression (ADS-K score > 17) & 1 & 19 \\
\hline Handedness (right, left, retrained left-handed) & $39,1,2$ & $37,1,4$ \\
\hline (Main) pain syndromes ${ }^{\dagger}$ & Controls & Chronic Pain \\
\hline Cervical/cervicobrachial pain & / & $7(5)$ \\
\hline Neuropathic pain & / & $3(3)$ \\
\hline Arthralgia & / & $9(6)$ \\
\hline Abdominal pain & / & $2(2)$ \\
\hline Myalgia & I & $1(0)$ \\
\hline
\end{tabular}

SD, Standard deviation; ADS-K, General Depression Scale - Short form; *education refers to $0=$ no degree, $1=$ lower secondary education, $2=$ secondary school, $3=$ A-levels, $4=$ university degree; **on an 11-point Numerical Rating Scale ( $0=$ no pain; $10=$ worst pain imaginable) on the day of testing. ${ }^{\dagger}$ The total amount of participants reporting different pain syndromes. In brackets, only the corresponding main pain category of each participant is listed.

TABLE 2 | Comparisons of MADER for different experimental conditions using independent samples t-tests.

\begin{tabular}{|c|c|c|c|c|c|c|}
\hline Tasks & MADER (SD) controls & MADER (SD) patients & $T$-value & $d f$ & $p$-value & Cohen's d \\
\hline \multicolumn{7}{|c|}{ POSITION MARKING } \\
\hline Overall & $4.1(1.5)$ & $5.1(1.9)$ & -2.686 & 80 & 0.009 & 0.58 \\
\hline Horizontal & $3.7(1.7)$ & $4.2(2.1)$ & -1.217 & 81 & 0.227 & 0.26 \\
\hline Vertical & $3.7(1.8)$ & $4.4(2.0)$ & -1.852 & 81 & 0.068 & 0.37 \\
\hline \multicolumn{7}{|l|}{ Unfamiliar } \\
\hline Vertical & $5.0(2.6)$ & $6.1(2.9)$ & -1.782 & 80 & 0.079 & 0.40 \\
\hline \multicolumn{7}{|c|}{ NUMBER NAMING } \\
\hline Overall & $3.4(0.9)$ & $4.4(1.4)$ & -4.075 & 68.205 & $<0.001^{*}$ & 0.85 \\
\hline \multicolumn{7}{|l|}{ Familiar } \\
\hline Horizontal & $3.1(1.3)$ & $4.1(2.4)$ & -2.298 & 81 & 0.024 & 0.52 \\
\hline Vertical & $3.5(1.4)$ & $4.2(1.6)$ & -1.987 & 81 & 0.05 & 0.47 \\
\hline
\end{tabular}

On the left, the Mean Absolute Deviation from the Expected Respective Response (MADER) is shown for each subtask of number line experiments for controls and pain patients. On the right, results of statistical analyses for differences between group MADERs for each experimental condition are displayed. SD, standard deviation; ${ }^{*} p<0.005$ (Bonferroni-corrected alpha-level). 
TABLE 3 | MADER and dependent t-statistics for low- and high-distance stimuli of the number line estimation tasks for chronic pain patients and controls.

\begin{tabular}{|c|c|c|c|c|c|c|c|c|c|c|}
\hline \multirow[t]{2}{*}{ MADER } & \multicolumn{5}{|c|}{ Number naming } & \multicolumn{5}{|c|}{ Position marking } \\
\hline & $\begin{array}{c}\text { Low } \\
\text { distance }\end{array}$ & $\begin{array}{c}\text { High } \\
\text { distance }\end{array}$ & $\mathbf{T}$ & df & $p$ & $\begin{array}{c}\text { Low } \\
\text { distance }\end{array}$ & $\begin{array}{c}\text { High } \\
\text { distance }\end{array}$ & $\mathbf{T}$ & df & $p$ \\
\hline MADER (SD) controls & $3.5(1.2)$ & $3.3(1.2)$ & -1.125 & 41 & 0.267 & $3.8(1.7)$ & $4.3(1.7)$ & 1.994 & 41 & 0.053 \\
\hline MADER (SD) patients & $4.5(1.6)$ & $4.4(1.9)$ & 0.410 & 40 & 0.684 & $4.3(1.7)$ & $5.8(2.5)$ & 4.860 & 39 & $<0.001$ \\
\hline
\end{tabular}

TABLE 4 | Descriptive results from the subtests of the computerized TAP battery for chronic pain patients and controls separately.

\begin{tabular}{lcc}
\hline Neuropsychological tests & $\begin{array}{c}\text { Controls M } \\
\text { (SD) }\end{array}$ & $\begin{array}{c}\text { Chronic pain } \\
\text { patients M }\end{array}$
\end{tabular}

(SD)

\section{COVERT SHIFT OF ATTENTION}

$\begin{array}{lcc}\text { Valid trial-right target } & 316.0(63.0) & 323.0(59.1) \\ \text { Valid trial-left target } & 322.6(67.1) & 326.8(67.8) \\ \text { Invalid trial-right target } & 374.2(88.0) & 379.8(75.8) \\ \text { Invalid trial-left target } & 352.0(91.8) & 355.6(72.0) \\ \text { SUSTAINED ATTENTION } & & \\ \text { Omissions 0-5 min. } & 3.0(2.9) & 2.9(2.5) \\ \text { Omissions 5-10 min. } & 3.0(2.6) & 4.0(3.6) \\ \text { Omissions 10-15 min. } & 2.7(2.5) & 3.7(3.3) \\ \text { WORKING MEMORY } & & 2.7(3.2) \\ \text { Errors } & 1.7(2.0) & 1.7(2.6) \\ \text { Misses } & 1.3(1.6) & \end{array}$

In covert shift of attention, values are given in milliseconds. For sustained attention and working memory, absolute values are reported. 